\title{
DOS REFLEXIONES PARA LA CONSTRUCCIÓN DOGMÁTICA DE LA FASE DE CORROBORACIÓN EN LA COLABORACIÓN EFICAZ
}

\section{TWO REFLECTIONS FOR THE DOGMATIC CONSTRUCTION OF THE CORROBORATION PHASE IN EFFECTIVE COLLABORATION}

\author{
Williams Alexander Robles Sevilla \\ Máster Iberoamericano en Políticas Anticorrupción \\ Universidad de Salamanca \\ https://orcid.org/0000-0002-6415-2703 \\ alex.robles.s@hotmail.com \\ España
}

\section{SUMARIO}

- Introducción.

- La fase de corroboración en el modelo de colaboración eficaz peruano.

- Primera reflexión: La corroboración o verificación de la información aportada por el colaborador desde la epistemología del proceso penal.

- Segunda reflexión: Se necesita el desarrollo dogmático de la fase de corroboración o verificación de la información aportada.

- Conclusiones

- Referencias bibliográficas.

\section{RESUMEN}

El presente artículo tiene por finalidad dedicar dos reflexiones para la construcción dogmática de una fase de corroboración o verificación de la información que aporta un aspirante a colaborador eficaz previa a la presentación del acuerdo y su homologación judicial. La primera insiste en cambiar la perspectiva de análisis de la colaboración eficaz que ha sido meramente operativa, para comenzar a preguntarnos si es posible aplicar métodos o criterios epistemológicos para reducir la desconfianza en la declaración de un colaborador eficaz. La segunda se inclina por desarrollar los elementos esenciales de la fase de corroboración o verificación, de tal manera que sirvan de sustento para el empleo de razonamiento que corrobore o verifique dicha información, lo que constituye una tarea pendiente.

\begin{abstract}
The purpose of this article is to devote two reflections for the dogmatic construction of a phase of corroboration or verification of the information provided by an effective applicant for collaborator prior to the submission of the agreement and its judicial approval. The first insists on changing the perspective of analysis of effective collaboration that has been merely operational, to begin to ask us whether it is possible to apply epistemological methods or criteria to reduce mistrust in the statement of an effective collaborator. The second is inclined to develop the essential elements of the corroboration or verification phase in such a way as to serve as a basis for the use of reasoning that corroborates or verifies that information, which is a pending task.
\end{abstract}

\section{PALABRAS CLAVES}

Procedimiento legal, Derecho penal, colaboración eficaz.

\section{KEY WORDS}

Legal process, criminal law, effective collaboration. 


\section{INTRODUCCIÓN}

"Hay puñales en las sonrisas de los hombres, cuanto más cercanos son, más sangrientos"

La lucha contra los delitos no convencionales se encuentra enmarcada dentro de los lineamientos que se definen en la política criminal del Estado. La política criminal es "el conjunto de métodos por medio de los cuales el cuerpo social organiza las respuestas al fenómeno criminal" (Delmas-Marty citado por Binder, 1997, p.33) y esta se encarga de definir la orientación del sistema penal y sus subsistemas, que son el Derecho penal, el Derecho procesal penal y la Criminología. Para Binder (1997), la integración funcional de estos subsistemas tiene como consecuencias, primero, que existe una coherencia entre ellos que tiene como eje la política criminal del Estado y, segundo que los subsistemas trasladan y adaptan las decisiones político criminales en su regulación orgánica y normativa.

En ese sentido, el Derecho procesal penal como subsistema también se encuentra delimitado por las decisiones político criminales que toma el Estado. Frente a los delitos de gran lesividad o complejidad como los delitos contra la administración pública, corrupción de funcionarios ${ }^{1}$, tráfico ilícito de drogas, lavado de activos, terrorismo y todos aquellos cometidos por una organización criminal ${ }^{2}$,

1 Intentar conceptuar a la corrupción como fenómeno social implica dificultades relacionadas a sus difusos componentes que impiden llegar a una definición concreta, por ello, existe acuerdo que de manera general se le entienda como el "abuso de poder otorgado (que puede ser público o privado) para el beneficio privado" (Transparencia Internacional, 2020). En el ámbito penal la dificultad se acrecienta, sin embargo, entre las pautas más resaltantes para identificar las conductas que podrian configurar tipos penales se encuentran los establecidos por la Convención de las Naciones Unidas contra la Corrupción en los que se incluye el cohecho, tráfico de influencias, abuso de funciones, encubrimiento, malversación, uso indebido de informaciones clasificadas, lavado de activos o blanqueo de capitales, delitos tributarios y contables y delitos de obstrucción a la justicia (Convención de las Naciones Unidas contra la Corrupción, 2003).

2 Entre las definiciones más representativas son de la Convención de las Naciones Unidas contra la Delincuencia Organizada Transnacional y sus dos protocolos adicionales realizado en la Conferencia de Palermo - Italia, suscrito por el Perú el 14 de diciembre del año 2000, que en su art. 2 refiere los conceptos de grupo delictivo organizado y grupo estructurado, en un intento de definir la compleja realidad. Mientras que en el Perú, tenemos la Ley $\mathrm{N}^{\circ}$ 30077, Ley contra el crimen organizado, de fecha 26 de julio de 2013 , que en el artículo $2^{\circ}$ refiere que: "se considera organización criminal a cualquier agrupación de tres o más personas que se reparten diversas tareas o funciones, cualquiera que sea su estructura y ámbito de acción, que, con carácter estable existe la tendencia de regular normativamente especialidades procedimentales y mecanismos procesales extraordinarios con la finalidad de lograr una mayor eficacia en la investigación. Sin duda, el fundamento de estas decisiones, parte por reconocer que los medios de investigación comunes $\mathrm{u}$ ordinarios son ineficaces frente a este tipo de criminalidad, así refiere Gómez (2004) que:

Pretender combatir esta modalidad delictiva con las mismas vías legales que las arbitradas para la delincuencia común, resultaría absolutamente inoperante. La imposibilidad aludida ha provocado una línea ascendente de especialización y diferenciación de la normativa contra el crimen organizado, que permite distinguir, en una primera sistematización entre medidas punitivas e investigadoras (p. 40).

Entre las características de estos mecanismos extraordinarios de investigación, es la permanente tensión que originan en su aplicación con los derechos y garantías del imputado. Su finalidad, que no es otra que la eficacia entra en colisión con el respeto de los derechos fundamentales del imputado, lo cual, ha llevado muchas veces a cuestionar su legitimidad y constitucionalidad en los procesos penales acusatorios modernos, denominándolos incluso, como manifestaciones de un derecho procesal penal del enemigo ${ }^{3}$. Sin embargo, no se debe buscar un regreso a mecanismos de carácter inquisitivo que en términos de eficacia pretendían encontrar al culpable en el menor tiempo posible, pues desde los postulados de los filósofos iluministas ha quedado demostrado que no se logra la $<$ verdad de los hechos $>$ con esos instrumentos.

En el caso de la incorporación de fórmulas del denominado Derecho penal premial, como lo es el arrepentido o la colaboración eficaz, tenemos diversos antecedentes que se pueden citar según sea el sistema jurídico que se analice. Sin ánimo de exhaustividad, podemos afirmar que en la familia jurídica del common law, en el derecho anglosajón británico

o por un tiempo indefinido, se crea, existe o funciona, inequivoca y directamente con la finalidad de cometer uno o más delitos graves" (Ley $\mathrm{N}^{\circ} 30077$, art. 3).

3 Entre las principales características de la extensión del derecho penal del enemigo al proceso penal se encuentra la relativización de garantías del imputado, como es el caso de las prohibiciones probatorias cuando se desarrollan mayores excepciones a la exclusión de la prueba ilicitamente obtenida (Riquert, 2011) (Muñoz,2008) (Portilla,2004) (González, 2007). 
corroboración en la colaboración eficaz

Two reflections for the dogmatic construction of the corroboration

phase in effective collaboration

tenemos como antecedentes el witness crown, $\mathrm{y}$ en el derecho anglosajón norteamericano, el antecedente lo encontramos en el sistema de acuerdos conocido como plea bargaining ${ }^{4}$, que ha servido de modelo para las legislaciones europeas, lo que no debe confundirse con la figura, ahora en boga, del whistleblower ${ }^{5}$ que se desenvuelve en un ámbito administrativo de prevención de riesgos ${ }^{6}$.

En el sistema eurocontinental, entre las fórmulas de regulación podemos citar se encuentra al coimputado colaborador del derecho penal español, cuya importancia en establecer criterios valoración para su declaración ha sido incuestionable, y como un antecedente directo, tenemos al pentiti o arrepentido implementado en la legislación italiana desde la década de 1970 en la lucha contra el crimen organizado de carácter mafioso $^{7}$, el narcotráfico y el terrorismo. Respecto al arrepentido, en la década de

4 El plea bargaining es una herramienta político criminal anclada sólidamente en el ordenamiento jurídico penal norteamericano, asi se puede decir de esta institución procesal que "al final de un procedimiento más o menos informal, sellado por una convención escrita presentada para homologación al juez en audiencia pública, la fiscalia y el abogado de la defensa acuerdan una pena inferior a la pena máxima prevista por la ley, a cambio de la renuncia del acusado a un proceso con jurado y a los derechos de la defensa que le son propios" (Garapon y Papadopoulos, 2008, p.57). La mayor discrecionalidad del Ministerio Público genera que estos acuerdos se extiendan no solo a la aceptación de responsabilidad, sino también, a la aportación de información con el beneficio que puede llegar a la exención de pena; ello también ha generado criticas desde la doctrina que la puede considerar como una fuente de coerción para el imputado (Langbein, 2001).

5 La traducción correcta del idioma inglés sería el informante o soplón.

6 En efecto, en el sistema norteamericano la participación del whistleblower "parece emplearse exclusivamente para los casos en que el delator es o ha sido empleado de una empresa o de la administración, no tanto cuando pertenece a una organización per se delictiva como puede ser una banda terrorista o de narcotraficantes" (Ragués, 2006, p. 4), lo que lo diferencia conceptualmente del arrepentido o colaborado eficaz. A partir de la suscripción de la Convención de Naciones Unidas contra la Corrupción del año 2003, se ha reconocido la necesidad de que los Estados adopten las medidas que permitan la denuncia de actos de corrupción cometidos por funcionarios públicos, lo que constituye un fundamento para su incorporación mediante los canales de denuncia en los denominados compliance programs que son implementados a las empresas y organizaciones públicas y privadas en los que se evidencia tanto irregularidades como delitos (Ortiz, 2018).

7 Existe también una dificultad por conceptuar el término de mafia, pues es un "termino polisémico que se refiere a hechos diferentes según los contextos, las circunstancias, las intenciones y los intereses de quien lo usa. Es dificil identificar un tema, una tipología o una sucesión de fenómenos homogéneos entre si que puedan agruparse bajo la voz mafia, y es igualmente difícil evitar la impresión de que es precisamente esa amplitud e indeterminación de los campos de aplicación lo que ha hecho la fortuna de esa palabra" (Lupo, 2016, p. 16). los años 90' se emitieron disposiciones normativas para regular in extenso sus fases, que "ha perseguido el propósito de privilegiar progresivamente al arrepentido a fin de lograr su colaboración con los investigadores y la denuncia a las autoridades de sus cómplices o de los delitos cometidos por la organización" (Montoya, 2001, p. 245), los que han servido de modelo para la regulación inicial del arrepentido en nuestra legislación peruana.

En un escenario similar a lo que sucedía en Italia, en el Perú, durante la década de los años 90' y en el contexto de la lucha contra las organizaciones terroristas como Sendero Luminoso y el Movimiento Revolucionario Túpac Amaru, que citamos como las más representativas por su gran alcance nacional, cantidad de miembros y métodos sanguinarios para imponer el terror en la población urbana y rural; se declaró el Estado de Emergencia Nacional $^{8}$ que llevo a la implementación de una legislación penal de emergencia, en la que se propugnaba en su regulación un mayor incremento de penas, así como, cambios significativos en la investigación y procesamiento en la persecución del delito de terrorismo.

En ese contexto, la implementación del arrepentido también tuvo como fundamento la eficacia en la persecución de los delitos graves como el terrorismo. Entre las disposiciones más resaltantes se pueden citar: El Decreto Ley $\mathrm{N}^{\circ} 25499$, de fecha 12 de mayo de 1992 , se reguló el arrepentimiento sobre Delito de Terrorismo para todos los delitos comprendidos en el Decreto Ley $\mathrm{N}^{\circ} 25475$, de fecha 5 mayo de 1992, que regulaba las sanciones para el delito de terrorismo; asimismo, mediante el Decreto Supremo N ${ }^{\circ}$ 015-93-JUS, se aprueba su reglamento, estableciéndose disposiciones operativas. Luego, mediante el Decreto Ley $\mathrm{N}^{\circ} 25582$ de fecha 24 de junio de 1992, se amplía su aplicación para otros delitos en los que el Estado se encuentre como agraviado, entiéndase delitos contra la administración pública, corrupción de funcionarios, entre

8 Mediante el Decreto Ley $\mathrm{N}^{\circ} 25418$, de fecha 30 de diciembre de 1991, Ley de Bases del Gobierno de Emergencia y Reconstrucción Nacional, que se sustentó como refiere en su exposición de motivos a "pacificar el país dentro de un marco jurídico que garantice la aplicación de sanciones drásticas a los terroristas, a fin de que, dentro de un clima de paz y orden interno nuestra sociedad se desarrolle adecuadamente" (Decreto Ley $\mathrm{N}^{\circ} 25418$ ) 
otros 9 . Con el fin de la dictadura de los años 90', se emitió la Ley $\mathrm{N}^{\circ} 27378$, de fecha 27 de octubre de 2001, Ley que establece los beneficios por colaboración eficaz en el ámbito de la criminalidad organizada, cambiándose la denominación del arrepentido por colaborador eficaz.

Dentro de esta amplia regulación del arrepentido o colaborador eficaz, queremos destacar en esta introducción, como se ha dispuesto la corroboración de la información aportada para determinar su eficacia. En tal sentido, se puede advertir que el arrepentido podrá acceder al beneficio de la exención de pena y remisión de pena, siempre que proporcione

voluntariamente información oportuna y veraz que permita conocer detalles de grupos $u$ organizaciones terroristas y su funcionamiento la identificación de los jefes, cabecillas, dirigentes y/o de sus principales integrantes, así como futuras acciones que con dicha información se impidan o neutralicen (Decreto Ley $N^{\circ} 25499$, artículo 1, II.).

Asimismo, en el Reglamento de la Ley de Arrepentimiento, se establecía cuál es la información debe considerarse como oportuna y veraz ${ }^{10}$, así como los supuestos sobre los cuales debe versar la información proporcionada $^{11}$; respecto al procedimiento

9 Sobre esta expansión de la institución, el penalista Peña Cabrera (1997) señaló que se estaba instrumentalizando, por cuanto lo idóneo era aplicarlo solo a los delitos de terrorismo, pero no a los delitos económicos o de corrupción de funcionarios, pues de esta manera se estaria politizando la justicia penal con un afán de persecución hacia los funcionarios del gobierno anterior o saliente.

10 Se considera como información que constará en el acta de declaración: b) Situación y cargo dentro de la organización terrorista a la que pertenece. C) Confesión veraz de los hechos delictivos en que hubiera participado. D) Información y veraz y oportuna sobre los grupos terroristas sus jefes, mandos, cabecillas y dirigente y otros a criterio de la autoridad. E) Información que permita impedir o neutralizar futuras acciones terroristas o de traición a la Patria. F) Firma e impresión digital del dedo índice derecho del solicitante (Decreto Supremo $N^{\circ}$ 015-93-JUS, artículo 11).

11 Entre los que se encuentran: a) Desarticular grupos u organizaciones terroristas. B) Capturar delincuentes terroristas. C) Descubrir bases de entrenamiento y centros de adoctrinamiento de grupos terroristas. D) Descubrir la vinculación de grupos terroristas por el tráfico ilícito de Drogas y otros delitos. E) Descubrir la infiltración de delincuentes terroristas en los diversos sectores de la población. F) Identificar personas y organizaciones que apoyan voluntariamente a través de diversos medios a grupos $\mathrm{u}$ organizaciones terroristas. G) Recuperar armamento, explosivos u otro material utilizado por los grupos terroristas. H) Liberar personal cautivo y/o secuestrado por los grupos terroristas. I) Conocer la forma y circunstancias de las acciones terroristas en las que participó. J) Evitar acciones y atentados terroristas (Decreto de verificación de la información, se dispone la participación de una unidad especializada de la Policía Nacional que será la encargada de verificar la información proporcionada que será plasmado en un informe dirigido a la autoridad correspondiente dentro del plazo de 5 días, prorrogable por igual plazo siempre que sea justificado (Decreto Supremo $\mathrm{N}^{\circ}$ 015-93-JUS, artículo 19 y 20). Es interesante revisar que la verificación tuvo el carácter de estrictamente secreto, pero se establecía que debería contener:

a) La identificación dactiloscópica del solicitante.

b) La formulación de la Hoja Básica Secreta.

c) Comunicación a las autoridades pertinentes.

d) Análisis, contraste y verificación de las informaciones.

e) Formulación del informe respectivo.

f) Cobertura con las mismas medidas de seguridad al solicitante. (Decreto Supremo $\mathrm{N}^{\circ}$ 015-93-JUS, artículo 24).

Por otro lado, en la Ley 27378 de fecha 27 de octubre de 2001, Ley que establece beneficios por colaboración eficaz en el ámbito de la criminalidad organizada, en la parte procesal se advierte que se dispone un escenario para que se realicen las diligencias previas al acuerdo. El fiscal dispondrá los actos de investigación, pudiendo ordenar la intervención de la Policía para que, bajo su conducción, realice las indagaciones previas y eleve un informe policial (Ley $\mathrm{N}^{\circ} 27378$, artículo 11); sin embargo, en el contenido del acta de colaboración no se establece que deba contener como se verificó la información, sino simplemente un relato de "los hechos a los cuales se refiere el beneficio y la confesión en los casos en que ésta se produjere" (Ley $\mathrm{N}^{\circ}$ 27378, artículo 12).

De lo expuesto, podemos ver que la regulación de la verificación de la información aportada por el arrepentido o el postulante a arrepentido, en la Ley de arrepentimiento en casos de terrorismo, se encontraba bajo la entera conducción de una unidad especializada de la Policía Nacional, que en un plazo muy breve de

Supremo $N^{\circ}$ 015-93-JUS, artículo 12). 
corroboración en la colaboración eficaz

Two reflections for the dogmatic construction of the corroboration

phase in effective collaboration

máximo 10 días debería realizar las diligencias necesarias; ello, responde a que el modelo de arrepentimiento respondía al asumido por el Código de Procedimientos Penales de 1940, en el cual la investigación era realizada por la Policía Nacional del Perú. Lo resaltante, es el grado de análisis y contraste que se requería plasmar en el informe policial, pero también que no existía ningún control al respecto. En la Ley $\mathrm{N}^{\circ} 27378$, Ley que establece beneficios por colaboración eficaz en el ámbito de la criminalidad organizada, por el contrario, si bien se hace referencia a que las diligencias previas al acuerdo las realice el Fiscal con la intervención de la Policía Nacional, no se hace referencia a un análisis y contraste sobre la verificación de la información que deba constar en el Acta de colaboración.

Por ello, consideramos que en ambas regulaciones la discrecionalidad de las autoridades es grande y esta tiende a crecer en el marco de un Estado de emergencia en el cual, las garantías constitucionales se relativizan y puede dar paso a la arbitrariedad, lo que sucedió en muchos de los casos de arrepentidos en la década de los años 90' que finalmente culminó con la anulación de las sentencias condenatorias que se basaban en declaraciones de arrepentidos por la justicia constitucional ${ }^{12}$. En tal sentido, en las siguientes líneas realizaremos un análisis y contribución para la construcción de la fase de corroboración de la información en el modelo de colaboración eficaz que hemos adoptado en el Código Procesal Penal de 2004 (en adelante CPP 2004).

\section{LA FASE DE CORROBORACIÓN EN EL MODELO DE COLABORACIÓN EFICAZ PERUANO}

La colaboración eficaz, a diferencia de las regulaciones anteriores que hemos desarrollado y de otros modelos asumidos en países como

$12 \mathrm{Al}$ respecto, puede revisarse el trabajo del profesor De La Jara (2016) quien desarrolla un análisis de los casos relativos a la utilización de la colaboración eficaz en los casos del destacamento Colina, tanto desde la perspectiva dogmática como jurisprudencial, así como un análisis de los pronunciamientos constitucionales sobre los mismos.
Brasil $^{13}$, Argentina ${ }^{14}$ o también es el caso de Colombia ${ }^{15}$, se la ha regulado como un proceso especial comprendido en los artículos 472 al 481-A del CPP de 2004, el cual fue modificado por el Decreto Legislativo 1301, Decreto legislativo que modifica el Código Procesal Penal para dotar de eficacia al proceso especial de colaboración eficaz, de fecha 29 de diciembre de 2016. En la doctrina nacional, se le ha entendido como un mecanismo propio de la justicia penal negociada, cuyo concepto:

Descansa en la figura del arrepentido, quien debe admitir o, en todo caso, no contradecir ante la autoridad los hechos delictivos que se le atribuyen, y proporcionar información suficiente, eficaz e importante en orden a neutralizar una actividad delictiva, identificar las lógicas de actuación criminal de una organización delictiva y a sus intervinientes, y/o entregar bienes

13 Actualmente, la colaboração premiada, ha sido reglamentada en todos sus extremos en la Ley $\mathrm{N}^{\circ} 12.850$ de fecha 2 de agosto de 2013. La concesión del perdón judicial está sometido a la producción de los siguientes resultados: I. La identificación de los demás coautores y participes de la organización criminal y las infracciones penales practicadas por ella; II. Revelar la estructura jerárquica y la división de tareas en la organización criminal; III La prevención de infracciones penales derivadas de las actividades de la organización criminal; IV. La recuperación total o parcial del producto o el provecho de las infracciones penales realizadas por la organización criminal; V. La localización eventual de la víctima con su integridad fisica preservada (Ley 12.850, 2013, artículo 4). Entre otras disposiciones destaca la regulación de los derechos del colaborador (Ley $12.850,2013$, artículo 5) y la obligación de ser asistido por su defensa en todos los actos de negociación, confirmación y ejecución (Ley 12.850, 2013, artículo 4 inc. 15).

14 La incorporación del arrepentido en Argentina se realizó con la Ley $\mathrm{N}^{\circ} 27.304$, de fecha 2 de noviembre de 2016 , establecer como presupuestos o requisitos para el acuerdo de colaboración: a) Brindar información o datos precisos, comprobables y verosimiles; b) Los datos o información aportada deben contribuir a: Evitar o impedir el comienzo, la permanencia o consumación de un delito; esclarecer el hecho objeto de investigación u otros conexos; revelar la identidad o el paradero de autores, coautores, instigadores o partícipes de estos hechos investigados o de otros conexos; proporcionar datos suficientes que permitan un significativo avance de la investigación o el paradero de víctimas privadas de su libertad; averiguar el destino de los instrumentos, bienes, efectos, productos o ganancias del delito; o indicar las fuentes de financiamiento de organizaciones criminales involucradas en la comisión de los delitos previstos en el presente artículo (Ley 27.304, art. 2).

15 En Colombia, encontramos disposiciones interesantes. En el Código de Procedimiento Penal Colombiano de 2004 se ha regulado la colaboración eficaz como un supuesto de procedencia para el principio de oportunidad, asi se señala que: "El principio de oportunidad se aplicará en los siguientes casos: (...) 5. Cuando el imputado colabore eficazmente para evitar que continúe el delito o se realicen otros, o aporte información esencial para la desarticulación de bandas de delincuencia organizada" (Ley 906, 2004, artículo 324). Asimismo, es relevante, destacar una disposición general en materia de acuerdos que dispone: "Son inexistentes los acuerdos realizados sin la asistencia del defensor. Prevalecerá lo que decida el imputado o acusado en caso de discrepancia con su defensor, de lo cual quedará constancia”. (Ley 906,2004, artículo 354). 
delictivos o ubicar su destino o paradero (San Martín, 2015, p. 871).

De igual manera, para Oré (2016):

Es un mecanismo de negociación penal que consiste, fundamentalmente, en el desarrollo de una actividad comisiva, tendiente a aportar a la autoridad en relación con: 1. La evitación de la producción del delito; 2. La evitación o atenuación de las consecuencias nocivas del delito ya consumado y/o 3. El acopio de los elementos de convicción necesarios para alcanzar cualquiera de los fines anteriores o garantizar la represión del delito a cambio de un determinado beneficio dentro de los legalmente establecidos. (pp. 623-624).

En ese sentido, el fundamento de su inserción en nuestro ordenamiento jurídico penal, señala Sánchez (2004), surge de la necesidad de desentrañar a la organización delictiva o criminal "que se esconde en el anonimato u ocultamiento, luego de conocerse los primeros elementos indiciarios de delito de corrupción de funcionarios, delitos de lesa humanidad y otros conexos a ellos, acontecidos en el Perú en la década pasada" (p. 245). Por ello, puede considerarse como una herramienta para combatir el crimen organizado, pues permite la obtención de información adecuada para el inicio de las investigaciones contra la criminalidad organizada (Rojas, 2012, p. 60).

Más allá de la discusión, siempre presente sobre la legitimación de este tipo de instituciones en cuanto a su aplicación en el Estado de Derecho, coincidimos con la posición de Miranda (2012) quien refiere, en líneas generales, que es más fructífera la discusión respecto de los presupuestos y requisitos de la colaboración eficaz que centrarnos solamente en el plano de la legitimación. Así pues, el reto actual, es que este tipo de instituciones procesales basadas en el consenso sobre la culpabilidad del imputado y el aporte de información valiosa en la lucha contra una criminalidad cada vez más compleja, sean interpretadas y aplicadas sin menoscabar sus derechos y garantías.

El modelo peruano de colaboración eficaz, tiene una fase de corroboración establecida en los artículos $473^{\circ}$ y siguientes, la cual, ha sido desarrollada con mayor amplitud en el Reglamento del Decreto Legislativo $N^{\circ} 1301$ aprobado mediante el Decreto Supremo $\mathrm{N}^{\circ}$ 007-2017-JUS, de fecha 29 de marzo de 2017.
En esta normativa, si bien, puede observarse un desarrollo específico de los pasos operativos que deben seguir los sujetos procesales en la fase de corroboración, consideramos que la doctrina no ha sentado las bases para un desarrollo dogmático de esta fase, centrando solamente su atención a la valoración de la declaración de colaborador eficaz y ahora también de un aspirante a colaborador en los procesos penales conexos, lo cual a todas luces es un error, por la importancia que tiene.

Así pues, desde la perspectiva de este trabajo, desarrollaremos argumentos que fundamentan nuestra posición de considerar a la fase de corroboración como una de las etapas centrales de la colaboración eficaz. y que debe ser sometida a un control riguroso desde que se inician las reuniones informales entre el Fiscal con el aspirante a colaborador, hasta que se emite la sentencia de colaboración eficaz. De esta manera, un desarrollo dogmático de la fase de corroboración permitiría un mayor debate respecto a la formación de la eficacia de la declaración del colaborador eficaz y a darle mayor coherencia a la interpretación normativa que se le pretenda brindar.

\section{PRIMERA REFLEXIÓN: LA CORROBORACIÓN O VERIFICACIÓN DE LA INFORMACIÓN APORTADA POR EL COLABORADOR DESDE LA EPISTEMOLOGÍA DEL PROCESO PENAL}

\section{Una cuestión de denominación: ¿De la corroboración a la verificación?}

El término corroborar puede ser utilizado en diversos contextos, ya sea en el ámbito común en el que se desarrolla la vida humana en sociedad, como en las ramas del conocimiento especializado del saber humano que comprenden las ciencias naturales $o$ sociales. Si recurrimos al diccionario de la Real Academia Española, corroborar proviene del latín corroborare, cuyo significado es "dar mayor fuerza a la razón, al argumento o a la opinión aducidos, con nuevos razonamientos o datos" (Real Academia Española, 2020); es decir la acción de corroborar consiste en aportar nuevos elementos o razonamientos para fundamentar un determinado criterio; en el Derecho, este concepto se utiliza también 
en muchos ámbitos, que para interés de la presente investigación nos restringiremos al análisis desde el Derecho procesal penal.

En el proceso penal, el término de corroborar puede hacer referencia o ser utilizada en diversos escenarios: por ejemplo, es común encontrar que fiscales al momento de iniciar o continuar la investigación del delito sustenten disposiciones fiscales en base a elementos de convicción que "corroboran" los hechos que se investigan hasta cierto grado probatorio necesario para proceder con las etapas del proceso penal (diligencias preliminares/ etapa de investigación preparatoria/ acusación fiscal - etapa intermedia), asimismo, también se utiliza cuando la fiscalía solicita medidas restrictivas de derechos, cautelares personales o reales y el juez de investigación preparatoria o juez de garantías competente, emite una resolución judicial en la que realiza un ejercicio de valoración de los elementos de convicción ofrecidos que determina si "corroboran" alguno de los presupuestos de dichas medidas.

Por otro lado, “corroborar" también es utilizado en el ámbito de valoración de los medios de prueba actuados en el juicio oral, como es el caso de los testimonios, en el que es frecuente encontrar resoluciones judiciales que motiven su valoración con frases como: El testimonio de $Y$ se encuentra corroborado por los testimonios de $\mathrm{X}$ y $\mathrm{Z}$ además de las documentales $\mathrm{A}, \mathrm{B}$, entre otros. Por ello, la corroboración de los testimonios puede conceptuarse como refiere Andrés Ibáñez (2009) como:

Dar fuerza a una afirmación inculpatoria de fuente testifical con datos probatorios de otra procedencia. Donde fuerza es calidad convictiva. Algo que solo transmiten los elementos de juicio que gocen de ella, es decir, los obtenidos de una fuente atendible y dotados de contenido informativo contrastado [...] Así pues, aquí, corroborar es reforzar el valor probatorio del aserto de un testigo relativo al hecho principal de la causa, mediante la aportación de datos de una fuente distinta, referidos no directamente a ese hecho, sino a alguna circunstancia que guarda relación con él, cuya constatación confirmaría la veracidad de lo declarado por el primero (p. 124 y 125).

Los principales aspectos de esta definición de corroboración se refieren a dos puntos centrales, el primero, que la corroboración de testimoniales se basa en elementos de juicio de fuente independiente y segundo, que se encuentren referidos al contenido del testimonio sea directamente o a alguna circunstancia del mismo. La corroboración se erige, pues, como uno de los puntos más importantes para determinar que el contenido del testimonio es conforme a la verdad, lo que encierra muchas dificultades ya que no siempre es posible encontrar otros testimonios que corroboren lo manifestado por un testigo o que se practiquen otras pruebas distintas que tengan el mismo resultado $y$, por lo tanto, que se corroboren entre sí (Nieva, 2012).

En ese sentido, el grado decorroboración de estas declaraciones será distinto dependiendo de la clase de testimonio que se someta a valoración, por ello, es que la doctrina suele distinguir entre las confesiones y testimonios, reservando este último término a aquellos terceros o personas ajenas al proceso que informan ante un juez, los sucesos o circunstancias que presenciaron con sus sentidos ${ }^{16}$. Dentro de las declaraciones testimoniales, encontramos según la doctrina a los testigos directo, de referencia o de oídas y como casos especiales de testimonios, las declaraciones del testigo víctima y los testigos sospechosos.

El artículo $158^{\circ}$ del CPP de 2004, establece reglas generales para la valoración de la prueba $y$ en concreto, en lo referente a nuestro tema de análisis señala en el inciso 2: "En los supuestos de testigos de referencia, declaración de arrepentidos o colaboradores y situaciones análogas, sólo con otras pruebas que corroboren sus testimonios se podrá imponer al imputado una medida coercitiva o dictar en su contra sentencia condenatoria". Conforme a lo expuesto, pareciera que la corroboración tal y como lo entiende el CPP de 2004 es una labor del juez al valorar la prueba personal sea fiable o no, siendo este último caso el de los colaboradores eficaces. Por ello, se puede afirmar que esta disposición es aplicable cuando la información obtenida en la colaboración eficaz es derivada al proceso penal conexo, en la cual será sometida al proceso y exigencias propias para un medio de prueba.

\footnotetext{
$16 \mathrm{Al}$ respecto, Devis Echandia (2002) refiere que: "La doctrina suele distinguir las declaraciones procesales según el sujeto que las haga y las denomina confesiones cuando provienen de una de las partes del proceso en que deben considerarse como pruebas y testimonios únicamente cuando son de otras personas" (p. 19).
} 
Sin embargo, como hemos mencionado anteriormente, la corroboración también se encuentra prevista como una fase en la colaboración eficaz, lo que no parece guardar coherencia con la corroboración establecida en el artículo 158 del CPP de 2004. En efecto, las corroboraciones de las declaraciones testimoniales sean de la víctima, coimputado y colaborador eficaz o de cualquier testigo, forman parte del razonamiento probatorio que empleará el juez para determinar su eficacia para sustentar una sentencia condenatoria. En ese sentido, una de las características de este razonamiento es que se enmarca dentro de una valoración individual y conjunta de las pruebas actuadas y que se deben plasmar en la motivación de la sentencia. Así, una sentencia epistémicamente correcta debería contener un análisis de las pruebas de cargo y de descargo actuadas como materialización del principio de contradicción en el proceso penal.

En este orden de ideas, consideramos poco acertada la denominación de fase de corroboración de la información aportada, por cuanto, conforme a la estructura del proceso especial de colaboración eficaz, el principio de contradicción no se materializa en ninguna disposición normativa. El Fiscal y el aspirante a colaborador eficaz no son partes confrontadas entre sí, sino que los une el interés de que el acuerdo se concretice y se culmine con una sentencia de colaboración eficaz, por ello, no existen ofrecimientos de elementos de convicción que contravengan la información aportada, más bien todos los actos de ambos sujetos se encuentran encaminados a su verificación; por otro lado, la participación de la víctima se encuentra limitada solo al cuestionamiento de la reparación civil.

Dicho esto, la labor que realiza el fiscal se parece más a una verificación de la información aportada por el aspirante a colaborador eficaz, para lo cual, puede ordenar se realicen diligencias con tal finalidad. Recordemos que, el antecedente directo de nuestra colaboración eficaz que se emitió en la década de los 90' fue la ley de arrepentimiento en casos de terrorismo, en la cual, no se habla de corroboración de la información sino de una verificación de la misma. Así pues, consideramos que, lo correcto sería considerar que en el proceso de colaboración eficaz la corroboración no puede ser entendida bajo los alcances del artículo 158 del CPP de 2004, sino que, tiene rasgos operativos de verificación y como veremos más adelante, también un fundamento epistémico que en conjunto con una interpretación garantista pueden servir como intento de racionalizar esta institución.

\section{¿La corroboración o verificación puede considerarse un método o criterio epistemológico en la colaboración eficaz?}

Nuestro CPP de 2004 asume el modelo cognoscitivo de enjuiciamiento penal, el cual refiere Ferrajoli (1995), se sustenta

en los procedimientos de verificación aportados por la epistemología acusatoria acusatoria o falsacionista tienen, así, su fundamento en el método de la prueba y refutación - por modus ponens y por modus tollens - ya tratado en el apartado 10.6 cuya transposición procesal se realiza a través de la separación y el reparto de papeles entre los tres sujetos del proceso: las dos partes, acusación y defensa a quienes compete respectivamente la prueba y la refutación, y el juez tercero, al que corresponde la decisión (...) (p. 606).

Ello nos lleva a preguntarnos si es posible adaptar estos procedimientos de verificación a un escenario como la colaboración eficaz, lo que no está exento de problemas. El primer problema, sin duda, proviene desde los propios fundamentos de la colaboración eficaz, basados en el consenso o negociación de la responsabilidad penal del coimputado, que ha generado posiciones muy críticas en la doctrina. Dentro de las diversas posiciones en contra de atribuir siquiera criterios epistemológicos a este tipo de instituciones, el más representativo es Ferrajoli (1995), quien sostiene la idea de la imposibilidad de que los mecanismos de negociación puedan asumir la epistemología falsacionista, tal y como lo postula el garantismo procesal penal.

De igual manera, Gascón (2004) afirma que existen reglas institucionales que tienen una naturaleza contra epistemológica, entre las que se pueden encontrar los límites temporales al proceso, formas de justicia negociada y límites probatorios; siendo las formas de justicia negociada las que afectan esencialmente la finalidad epistemológica del proceso penal; ya que, se institucionalizaría una "excepción a la regla epistemológica que establece: Para poder afirmar la verdad de un enunciado fáctico es 
corroboración en la colaboración eficaz

Two reflections for the dogmatic construction of the corroboration

phase in effective collaboration

necesaria prueba del mismo, sea esta directa, deductiva o indirecta" (p. 128).

Estas críticas, sin duda toman como base las negociaciones entre Fiscal y el imputado al estilo anglosajón o norteamericano como el plea bargaining, así como su recepción por los sistemas euro-continentales en las instituciones como el pattegiamento, conformidad $\mathrm{y}$ terminación anticipada. Ambos autores, consideran sus críticas también extensibles para las figuras de los arrepentidos, coimputados colaboradores y colaboradores eficaces, así pues, considera Ferrajoli (1995), este tipo de negociaciones por colaboración del imputado pueden convertirse en una "especie de justicia de cadí" (p. 749), ya que, el resultado queda sometido a una desmedida discrecionalidad del Ministerio Público sin participación por parte del juez, en cuanto a la valoración de los hechos.

Sin duda, las críticas son certeras y ciertamente, han contribuido a fomentar el debate respecto a los fundamentos de estas instituciones. Sin embargo, no podemos evitar rescatar el escenario político criminal actual, que precisamente ante la proliferación más visible hoy de la criminalidad organizada de alcance trasnacional inclusive, mediante acuerdos internacionales han propiciado su implementación. Por ello, y con la finalidad de brindar una propuesta de interpretación normativa que sirva a los jueces, quienes, lo quieran o no -independientemente de su postura ideológica - deben aplicar y valorar los elementos probatorios que surgen de este tipo de instituciones, consideramos pertinente abordar dos de los temas que más cuestionamientos más polémicos que Ferrajoli (1995) bien ha precisado:

- El ministerio público ha sido investido de un enorme poder de predeterminación tanto del método como del contenido del juicio, lo que contradice su naturaleza de "parte" en situación de igualdad con el imputado que es el rasgo más característico del sistema acusatorio - y compromete el principio constitucional de la obligatoriedad de acción penal (p. 750).

- El esquema se manifiesta en la alteración del objeto procesal que se sigue directamente de la de las figuras del delito. Si el presupuesto de la pena viene representado, más que por hechos delictivos determinados, por la personalidad terrorista sustancial de su autor, el proceso decae inevitablemente de procedimiento de verificación empírica de las hipótesis de la acusación a técnica de inquisición sobre la persona, es decir, sobre su subjetividad sustancialmente enemiga o amiga tal y como se expresa no sólo en los delitos cometidos sino también en su comportamiento procesal (...) Con ellas, el imputado, más allá de la relevancia y quizá el fundamento de sus revelaciones, forma filas con la acusación y da la prueba visible y cierta, más que de su culpabilidad o de la de sus compañeros, de su elección de campo anticriminal (pp. 821-822)

Ante estos argumentos, es innegable considerar que la colaboración eficaz como institución en abstracto, es contraepistemológica; sin embargo, a pesar de las críticas que desde la doctrina procesal se ha realizado a la regulación de la colaboración eficaz como proceso especial, la fase de corroboración de la información previa al acuerdo, establecida en el art. $473^{\circ}$ del CPP de 2004, podría servir como criterio o metodología epistemológica que minimizaría el perjuicio o la desconfianza ante esta declaración, si se compatibiliza con el falsacionismo y se le brindan las garantías constitucionales necesarias.

Esta postura se sustenta, primero, en precisar que la corroboración cumple dos funciones: a) Como diligencias de investigación, es decir como actividad de búsqueda de elementos corroborantes; y b) Como juicio o criterio de verificabilidad de la eficacia y veracidad de la información aportada por el aspirante a colaborador eficaz. Para lo que nos interesa en el presente aparado, la pregunta central es si ¿la corroboración como criterio de verificabilidad puede tener un fin epistemológico?, pues se trata de contrastar con elementos distintos propios de las diligencias de corroboración, si la información es eficaz, veraz y útil.

En tal sentido, una primera respuesta negativa, se sustenta en que, al ser un proceso especial no contradictorio, sin juicio oral y con una discrecionalidad plena del Fiscal con intervención judicial solo formal -, la contrastación como elemento epistemológico de la valoración probatoria no se encuentra presente, al no encontrarnos propiamente frente a pruebas. Este problema, es superado cuando la declaración del colaborador eficaz es utilizada en el proceso conexo, en el cual, si es sometido a todas las garantías y 
consecuentemente puede ser valorado luego de un juicio oral.

La respuesta positiva, que es la que se propugna en la presente investigación, se centra la premisa de que una rigurosa corroboración o verificación de la información como requisito previo al acuerdo de colaboración, serviría para aquellos casos en los que se decida aplicar el criterio de valoración del art. $158^{\circ}$ inc. 2 del CPP de 2004 que habilita que se utilice la declaración para sustentar medidas cautelares de carácter personal inclusive, lo que no sería necesario si nuestro modelo de colaboración eficaz hubiese optado por regularlo como un mero incidente dentro de un proceso penal principal; sin embargo, al no ser así, es indispensable que a este proceso especial se le revista de criterios epistemológicos y garantías procesales que lo justifiquen.

Desde esta perspectiva, consideramos que es indispensable precisar si es la verdad procesal en un grado de certeza subjetiva - como se conceptúa en el derecho procesal penal - lo que se obtendrá en el proceso de colaboración eficaz. Así pues, consideramos que de ninguna manera el grado de probabilidad de la información que ha sido proporcionada por el colaborador eficaz puede ser denominado como verdad procesal, por cuanto, no reviste el conjunto de garantías constitucionales necesarias y la estructura procesal que habilite la aplicación de los principios procesales.

En tal sentido, para que sea efectivamente prueba que pueda desvirtuar la presunción de inocencia deberá ser sometida todo este conjunto de garantías y normas procesales en el proceso penal conexo, en donde se podrá discutir todos sus efectos. Por ello, consideramos que la información proporcionada y obtenida no tendría carácter prueba, sino solo como un medio de prueba o elemento de convicción que podría sustentar una medida cautelar personal o real, conforme a los criterios establecidos en el artículo $158^{\circ}$ inciso 2 del CPP de 2004.

En consecuencia, consideramos vital que la fase de corroboración o verificación debe regirse bajo la metodología falsacionista, que llevado al ámbito del proceso penal deberá pasar por las etapas de: contrastación empírica, coherencia y aceptación justificada de la decisión. El resultado obtenido de esta fase, puede ser dividida en dos: a) la información incriminatoriamente propiamente dicha en la declaración del aspirante a colaborador $\mathrm{y}, \mathrm{b})$ la información que la corrobora. La diferencia del proceso especial de colaboración eficaz con otros mecanismos de justicia negociada, se encuentra principalmente en la prevalencia de la delación sobre cualquier otro elemento, inclusive sobre la confesión de los delitos materia de incriminación; por ello, la corroboración es importante epistemológicamente para tales efectos.

Con nuestros argumentos expuestos, no se quiere dar a entender que con la sola corroboración o verificación, todos los fundamentos esbozados en contra de esta institución deberían tomarse como superados y dejados de lado, sino que, por el contrario, la construcción teórica de la corroboración previa al acuerdo por sí sola es insuficiente para dar legitimidad epistemológica a este proceso especial, pero constituye un primer paso para seguir trabajando los fundamentos científicos que apoyen al legislador, a crear o reformar el procedimiento de colaboración eficaz y hacerlo más adecuado y coherente con el modelo de estricta legalidad y jurisdiccionalidad que plantea el garantismo penal.

\section{SEGUNDA REFLEXIÓN: SE NECESITA EL DESARROLLO DOGMÁTICO DE LA FASE DE CORROBORACIÓN O VERIFICACIÓN DE LA INFORMACIÓN APORTADA}

\section{Critica a la lógica operativa de la fase de corroboración o verificación}

En este apartado nos centraremos en las críticas que tengan relación directa con la fase de corroboración previa al acuerdo de colaboración eficaz. Tomaremos como referencia los estudios dogmáticos nacionales o extranjeros que se han elaborado y añadiremos nuestras propias reflexiones.

Una primera crítica proviene del riesgo de que se manifieste el sesgo de confirmación en la fase de corroboración. El problema que vemos en la regulación de la colaboración eficaz, se encuentra en su estructura normativa con la modificación del Decreto Legislativo 1301. Así pues, el art. 472, 473 y 473-A del CPP de 2004, solo habilitan la participación del Fiscal, Policía Nacional, el aspirante a colaborador 
corroboración en la colaboración eficaz

Two reflections for the dogmatic construction of the corroboration

phase in effective collaboration

y su defensa, así como el agraviado - este último al final de la fase de corroboración en el proceso de colaboración eficaz. De igual manera, el art. 13 del Reglamento del Decreto Legislativo 1301, establece que intervendrán obligatoriamente en la fase de corroboración el Fiscal y el colaborador.

Nuestro modelo de colaboración eficaz, establece la dirección de la fase de corroboración y posterior decisión de presentar el acuerdo de beneficios y colaboración eficaz al Fiscal. El Juez tiene competencia para realizar un control de legalidad del acuerdo de colaboración en cuanto al cumplimiento de sus requisitos, por lo que consideramos que su intervención tal y como se viene interpretando es meramente un control formal. En tal sentido, quien finalmente decide cuándo se encuentra corroborado la declaración del aspirante a colaborador eficaz es el fiscal.

Las diligencias de corroboración se encuentran bajo la dirección del Fiscal en las que también pueden participar la Policía Nacional, que al finalizar los actos de investigación que le son encomendados emitirá un informe policial. Respecto a la posibilidad de que la recogida de los elementos de convicción o corroborantes lo realice la Policía Nacional, la doctrina se ha manifestado en contra de ello si es que se le brinda una amplia discrecionalidad. En ese sentido, Nieva (2010) también incide en la importancia de esta fase dentro de la actividad probatoria en el proceso penal y, señalando que no debe abandonarse esta actividad a la Policía Judicial, puesto que, como se ha manifestado anteriormente no tiene por objetivo el respeto de la presunción de inocencia.

Así pues, en apariencia la actuación del fiscal en este proceso especial conforme al principio de objetividad, establecido en el Art. IV del Título Preliminar del CPP de 2004, garantizaría que solo se llegue a un acuerdo de beneficios y colaboración eficaz, cuando la información sea útil, eficaz y haya superado los filtros de la fase de corroboración. Sin embargo, como hemos señalado, no existe mayor control judicial sobre dicha fase, sino que se encuentra en el ámbito de la discrecionalidad del Fiscal, lo que propiciaría la existencia de un peligro de sesgos cognitivos o prejuicios en el razonamiento corroborativo de la información aportada por el aspirante a colaborador eficaz.
En efecto, si recurrimos a las bases psicológicas del razonamiento probatorio, nos tenemos que remitir a los procedimientos mentales mediante los cuales el ser humano procesa la información que percibe del mundo exterior, que han sido materia de estudio por parte de los psicólogos exponentes del movimiento cognitivo, entre los que se encuentra Kahneman (2017), quien afirma que en el proceso mental asociativo sobre la toma de decisiones, existen factores que privilegian una tendencia hacia la confirmación que a la duda. En las propias palabras del autor, señala que:

Las operaciones de la memoria asociativa contribuyen a una inclinación general a la confirmación. Cuando, por ejemplo, nos preguntan ¿Sam es simpático? Nos vendrán a la mente ejemplos del comportamiento de Sam diferentes de los que nos vendrían si hubieran preguntado ¿Es Sam antipático? Un intento deliberado de confirmar evidencias, conocido como estrategia de contrastación positiva, es también la manera en que el Sistema 2 contrasta una hipótesis. Contrariamente a las reglas de los filósofos de la ciencia, que aconsejan contrastar hipótesis intentando refutarlas, la gente (y los propios científicos con bastante frecuencia) busca datos que puedan ser compatibles con las creencias que actualmente tiene. Este sesgo confirmatorio del Sistema 1 favorece la aceptación acrítica de sugerencias y la exageración de la probabilidad de acontecimientos extremos e improbables. (Kahneman, 2017, p. 112).

Como vemos, "un sesgo cognitivo es una desviación sistemática, involuntaria e inconsciente de una norma o de un estándar de racionalidad al emitir un juicio perceptual o conceptual, al recordar un evento o al hacer una predicción" (Páez, 2019, p. 3). En particular, el sesgo confirmatorio evita la posibilidad de contrastar las hipótesis a solo buscar elementos que puedan servir de apoyo a su propia concepción ya definida. Este sesgo puede encontrarse en las diversas fases de la toma de decisiones que va desde la recopilación de información, al análisis e interpretación y almacenamiento de la misma. Los efectos de este sesgo han sido utilizados como refiere Muñoz (2011):

Para explicar la perseverancia de creencias (las creencias en determinadas personas permanecen intactas aun cuando la evidencia de estas creencias haya sido probada como falsa) y la polarización de la actitud (un desacuerdo es 
más polarizado, aun cuando las diferentes partes estén expuestas a las mismas pruebas). (p. 9)

En el caso de la colaboración eficaz, puede suceder que sea el propio Fiscal quien propicie un acuerdo con el imputado o investigado con la finalidad de que se someta a la colaboración eficaz, pues necesita esta información con urgencia; así que, cuando consigue que el imputado acceda a otorgar la información, las diligencias de corroboración van a ser dirigidas por un Fiscal bajo la influencia del sesgo de confirmación, que solo buscará elementos que corroboren lo manifestado a pesar del criterio objetivo que le impone el art. IV del Título Preliminar del CPP de 2004, sin aplicar la metodología de contrastación de hipótesis.

La amplia discrecionalidad del Ministerio Público en el proceso de colaboración eficaz $y$ el control de legalidad meramente formal por parte del Juez que homologa el acuerdo de colaboración eficaz, propicia un escenario que eleva el riesgo de la presencia de este sesgo ya sea consciente o inconscientemente, por lo que, consideramos una crítica válida hacia nuestra regulación normativa actual que no se hayan previsto medidas de control para evitar los efectos de este tipo de sesgos cognitivos.

Una segunda crítica, proviene de la posibilidad de se pueda aportar información falsa o se incrimine por motivos espurios. El colaborador eficaz según la normativa procesal penal peruana, no es un arrepentido propiamente dicho. No existe una confesión de su parte con un ánimo solamente de arrepentimiento y con el fin altruista de colaborar con la justicia, por el contrario, no se puede desconocer que su motivación de acogerse a este proceso especial radica en un interés de ser beneficiado o premiado por ello. Esta negociación entre el Fiscal y el aspirante a colaborador eficaz, constituye el objeto del proceso especial, de tal manera que si cumple con los requisitos establecidos en la norma procesal penal su beneficio premial puede inclusive ser de una exención de pena, con ello se evitaría los costos de un proceso judicial y una posible sentencia condenatoria.

Conviene entonces diferenciarlo de la figura del coimputado en este aspecto. En el caso del coimputado, no existe beneficio premial alguno, salvo que se haya sometido a la conclusión anticipada o conformidad procesal; por lo que, el único interés que podría perseguir cuando declare en contra de sus demás coimputados, sería el de exculpación como hemos precisado anteriormente. Así pues, los controles que se le asignan para evitar la posibilidad de que lo manifestado sea falso recae además de la corroboración de la información, en la evidencia de ausencia de incredibilidad subjetiva, es decir descartar los móviles espurios, tal y como lo ha afirmado la doctrina y la jurisprudencia mayoritaria.

En el caso del colaborador, si bien no descartamos que tenga un móvil espurio de exculpación, encontramos particularidades que merecen una atención distinta. Si hemos precisado que el interés del colaborador es el beneficio premial por la información que aporte, los factores que pueden incidir para que se aporte información o una sindicación falsa sobre los integrantes de la organización criminal y sus actividades, puede versar por ejemplo, al encontrarse sometido a una medida coercitiva personal y gracias a la colaboración eficaz desea evitar su prolongación o, en otro de los casos evitar que se le acuse o inicie una investigación en su contra, por lo que aporta información parcialmente verdadera para dichos efectos.

Y finalmente, como tercera crítica, puede suceder que se realicen diligencias de corroboración ilícitas. Como sucede en el proceso penal común, las diligencias que realiza la Policía Nacional bajo la dirección del Ministerio Público, tienen por finalidad realizar los actos de investigación necesarios para la averiguación de los hechos presuntamente delictivos. El marco legal de actuación de dichas diligencias se rige bajo las formalidades, presupuestos y requisitos establecidos en el CPP de 2004 y, en consecuencia, bajo la primacía del principio de legalidad procesal.

No obstante, en el proceso de colaboración eficaz donde predomina el secretismo y la discrecionalidad fiscal, existe un riesgo superior que en el proceso penal común de que se realicen diligencias o actos de corroboración que tengan por finalidad la corroboración de la información aportado con vulneración de derechos y garantías constitucionales que no podrían ser conocidas hasta luego de que se haya suscrito el acuerdo de colaboración y, se incorpore al proceso penal conexo. 


\section{Concepto, lógica e importancia de la corroboración o verificación en el acuerdo de colaboración eficaz}

El concepto de corroboración que manejaremos para hacer referencia a esta etapa de verificación de la información aportada por el aspirante a colaborador eficaz, debe abarcar todos los ámbitos en los que desenvuelve dicha actividad, distinta al concepto de corroboración que se maneja en el artículo $158^{\circ}$ inciso $2 \mathrm{del}$ CPP de 2004.

Desde nuestra perspectiva corroborar no implica una mera acreditación de mediante elementos objetivos distintos, sobre si lo aportado por el aspirante a colaborador eficaz es verosímil o no, descartándose con ello el razonamiento sobre la información obtenida o elementos de convicción recabados como lo propone Castillo (2017); sino que, puesto en su dimensión completa abarcaría diversas facetas que necesariamente deben estar presentes en el Acta de colaboración eficaz que posteriormente podrá ser homologado o no por el Juez. Así pues, la estructura de la corroboración que proponemos, conforme al desarrollo anterior, sería el siguiente:

Tabla $N^{\circ}$ 1: Estructura y pasos de la fase de corroboración previa al acuerdo

\begin{tabular}{|c|l|}
\hline SUB FASES & \multicolumn{1}{|c|}{ CONTENIDO } \\
\hline $\begin{array}{c}\text { Sub-fase de } \\
\text { diligencias de } \\
\text { corroboración }\end{array}$ & $\begin{array}{l}\text { Realización de diligencias } \\
\text { de investigación conforme al } \\
\text { marco procesal del CPP }\end{array}$ \\
\hline $\begin{array}{c}\text { Sub-fase del } \\
\text { razonamiento } \\
\text { corroborativo de } \\
\text { la información } \\
\text { aportada }\end{array}$ & $\begin{array}{l}\text { Coherencia del relato. } \\
\text { Constrastación de hipótesis } \\
\text { Utilización del grado de } \\
\text { verosimilitud. }\end{array}$ \\
\hline $\begin{array}{c}\text { Sub-fase de } \\
\text { motivación del } \\
\text { razonamiento } \\
\text { corroborativo en el } \\
\text { acuerdo }\end{array}$ & $\begin{array}{l}\text { Se justifica concretamente el } \\
\text { razonamiento corroborativo } \\
\text { en todos sus alcances. }\end{array}$ \\
\hline
\end{tabular}

Fuente Propia (2020)

Elaboración propia (2020)

Es importante el desarrollo de cada uno de estos elementos de la fase de por cuanto, se aprecia por la posibilidad de que en base a las declaraciones de un colaborador eficaz (hasta de un aspirante a colaborador, inclusive) y de la información obtenida en las diligencias de corroboración, se pueda condenar al aspirante a colaborador eficaz y, a la vez, emitir medidas coercitivas y limitativas de derechos; lo que no evita a que en aquellos momentos procesales, se realicen las corroboraciones en dichos procesos conexos, pero que coadyuva a otorgarle mayor verosimilitud a la información aportada.

En ese sentido, la Corte Suprema acertadamente, ha precisado lo siguiente:

La fase de comprobación de la información es la más importante, en tanto de ella depende que se llegue a un acuerdo y ulteriormente el colaborador pueda ser sujeto de beneficio mediante sentencia dictada por juez competente. De ahí que, la sola sindicación no es suficiente para concluir que la información sea veraz. Hace falta prueba de corroboración externa a la declaración incriminatoria, ello como exigencia derivada de la garantía constitucional a la presunción de inocencia; en la medida que el aspirante a colaborador puede brindar información escasamente fiable, por el solo interés de obtener beneficios. Por lo tanto, la corroboración ha de ser rigurosa, con el fin de llegar a la verdad de los hechos. (Corte Suprema de Justicia, Casación $\mathrm{N}^{\circ}$ 852-2016-Puno, fundamento 7).

De esta manera, marcamos nuestra posición desde el inicio, que consiste en considerar que la información aportada y obtenida por el aspirante a colaborador eficaz y en las diligencias de corroboración, será idónea para ser utilizada en los procesos conexos, si y solo sí, ha superado los filtros establecidos en el proceso especial de colaboración eficaz, es decir, que se culminado con dicho proceso. Es evidente que nuestro criterio coincide con un sector minoritario de la doctrina procesal penal que ha desarrollado el tema y, va en contra de la interpretación mayoritaria que ha realizado la jurisprudencia.

\section{¿Es la corroboración o verificación un principio del proceso de colaboración eficaz?}

Respecto a este punto, cabe señalar que en la doctrina nacional se ha escrito muy poco. $\mathrm{Y}$ dentro de lo que se ha escrito llama la atención como algunas veces, fases propias del procedimiento o inclusive actividades que realizan una o varios sujetos del proceso 
penal, pueden inspirar o propiciar que algunos autores las cataloguen como categorías lógicojurídicas también denominados principios procesales, en la creencia de que al hacerlo se afirma su importancia para dicho proceso. Cabe señalar que esto último es una mera especulación de los motivos de dichos autores, sin embargo, ello no evita la crítica frente a esta práctica dentro de la academia procesal penal peruana.

Así pues, cabe preguntarnos si es posible considerar a la corroboración como un principio en la colaboración eficaz. Al respecto, cabe preguntarnos, conforme a lo que hemos expuesto anteriormente, y dado la variedad de veces y momentos en el proceso en el que es utilizado el término de corroboración si vale considerarla como un principio $\mathrm{y}$, si esto fuera así, cuáles serían sus alcances y contenido esencial.

Para empezar, un principio del proceso como categoría lógico fundamental tiene ánimo de universalidad y que inspira la labor interpretativa del juzgador, por lo que tienen un contenido esencial definido dogmática y jurisprudencialmente. La corroboración como lo hemos mencionado anteriormente, se encuentra dentro del ámbito de la valoración y motivación de la prueba, siendo el sinónimo de probar. La corroboración no es un principio del proceso penal que puede modelar por sí mismo la estructura, etapa y funciones de los sujetos del proceso penal o como limitador de la arbitrariedad del Estado; sino que, actúa como un criterio epistemológico de veracidad de los medios de prueba actuados, sean testimoniales o documentales.

Así pues, la corroboración de la declaración del colaborador eficaz no puede ser considerada un principio del proceso, sino, metodología en la valoración de la prueba. Por otro lado, la corroboración previa al acuerdo, que es el tema de interés en la presente investigación, tampoco puede ser considerado un principio procesal, porque es una etapa del proceso especial de colaboración eficaz, que cumple diversas funciones como criterio epistemológico para determinar la utilidad o eficacia de la información aportada por el aspirante a colaborador eficaz, no se está pues ante una actividad de valoración de medios de prueba. La corroboración, utilizada así, es una fase previa al acuerdo de colaboración eficaz cuya finalidad no es otra que la verificación de la información aportada.

En esa línea de interpretación, a pesar de no considerarla como un principio procesal, la importancia de la corroboración ha quedado plenamente acreditada en el apartado anterior, en el que hemos rescatado su inserción como criterio epistemológico de veracidad, que viene a menguar la inherente falta de credibilidad de la declaración del aspirante a colaborador eficaz.

\section{Elementos esenciales de la fase de corroboración o verificación de la información en el acuerdo de colaboración eficaz}

\section{Condiciones necesarias previas}

\section{a. La voluntariedad y la defensa penal efectiva en las reuniones previas al acuerdo}

No es nuestra intención realizar un desarrollo integral de la fase del acuerdo de colaboración eficaz, sino simplemente dejar constancia de la importancia que tienen estos aspectos de cara a la fase de corroboración, pues no tendría validez una información aportada viciada desde un inicio, aun cuando haya superado los filtros de la fase de corroboración. En ese sentido, dado el carácter de negociación de la colaboración eficaz, es inevitable pronunciarnos por dos requisitos que consideramos indispensables para el éxito del proceso de colaboración eficaz, que son la voluntariedad y el ejercicio del derecho de defensa.

Sobre el primer aspecto de la voluntariedad, debemos remitirnos por el amplio tratamiento que se le ha brindado a la doctrina y jurisprudencia norteamericana. En el plea of guilty (aceptación de cargos), el Juez realiza en primer lugar, un examen de capacidad de comparecer al juicio en el ejercicio de sus plenas facultades; en segundo lugar, verifica la voluntary de su declaración, es decir que su declaración se encuentre libre de coerción o producto de haber sido sometido a violencia psíquica o física que le obligue a confesar (Rodríguez, 1997). Aun cuando críticamente Langbein (2001) haya señalado que "el acuerdo (plea areegment) es la fuente de la coerción" (p. 15), dejar de lado este requisito traería aún mayores márgenes de arbitrariedad. 
corroboración en la colaboración eficaz

Two reflections for the dogmatic construction of the corroboration

phase in effective collaboration

Críticamente a la regulación de la voluntariedad, Laudan (2013) al comentar los fallos de la Corte Suprema Estadounidense refiere que:

La corte suprema rechaza que el criterio para la admisión de las confesiones debe ser la relevancia y no la voluntariedad. En 1961, por ejemplo, la Corte argumentó que para decidir si una confesión ha sido otorgada voluntariamente (y es, por ello admisible), sería inapropiado considerar si ésta era probablemente verdadera (En el caso Rogers v. Richmond, la Corte argumentó que la impugnación de un supuesto otorgamiento voluntario de una confesión no puede resolverse usando "un estándar jurídico que tenga en cuenta las circunstancias de (su) probable verdad o falsedad" 365 US 534 (1961)). Es decir, una confesión que sea internamente coherente y que haya sido ampliamente corroborada, no obstante, será excluida a menos que el Estado pueda demostrar que fue otorgada voluntariamente (...) Esta situación es al menos extraña. (...) Desde mediados del siglo XX, la voluntariedad ha cobrado importancia en sí misma, perdiendo su anterior rol como test de la verdad de una confesión. Lo que fue introducido originariamente como ayuda para la búsqueda de la verdad ahora se ha convertido en un impedimento capaz de superar a la verdad misma. (p. 252).

No obstante, lo expuesto por Laudan, nuestra posición es considerar a la voluntariedad como un requisito indispensable de igual o más valor que la relevancia de la información que se aporta por el colaborador eficaz; de igual manera, la voluntariedad se encuentra íntimamente ligada al ejercicio efectivo del derecho de defensa del aspirante a colaborador eficaz. Respecto a este último aspecto de la defensa penal efectiva, se ha establecido conforme lo señala Rodríguez (1997), que la falta de una defensa penal no invalida el acuerdo, pero se extreman cuidados en caso no se cuente con el ejercicio de dicho derecho:

La importancia de la asistencia letrada es tal que los Jueces, reputarán como ha reconocido implícitamente la Supreme Court, voluntary and knowing la declaración del acusado que esté asistido por un abogado (puesto que se supone que estos han avisado adecuadamente a sus defendidos), por lo que aquellas pleas que no se produzcan de este modo serán más cuidadosamente revisadas por el Juez. Ello no quiere decir que estas declaraciones no sean válidas, sino que el record deberá demostrar que el acusado fue informado de este derecho y que él voluntariamente renuncio al mismo. (p. 54).
Desde el derecho comparado rescatamos la regulación en el derecho brasileño, que se establece la obligatoriedad de que el imputado se encuentre asesorado por su abogado defensor en las negociaciones con el Fiscal (Ley 12.850, 2013, artículo 4, inc 6. Inciso 15). A diferencia de esta regulación, el ordenamiento procesal penal peruano ha optado por una defensa facultativa en las negociaciones previas, así pues, tenemos la posibilidad de que el Fiscal pueda celebrar reuniones con los colaboradores con o sin la presencia de sus abogados, que puede ser materializado en un convenio preparatorio (CPP de 2004, artículo 473 inciso 3 ), lo que, sin duda, puede convertirse en un instrumento de coacción si no se extreman los controles.

\section{La necesaria idoneidad del aspirante a colaborador eficaz y credibilidad minima de la información que aporta}

El aspirante a colaborador eficaz, debe tener las cualidades de la idoneidad conforme a lo establecido en los artículos 474 y 475 del CPP de 2004, de los cuales puede interpretarse que debe ser necesariamente un integrante de la organización criminal e inclusive, pueden ser los jefes, cabecillas o dirigentes principales de organizaciones delictivas; es decir, todo aquel que puede entregar la información útil y eficaz que cumpla con alguna de las finalidades de la colaboración eficaz. En igual sentido y, con mayor precisión, el art. 4 del Reglamento del Decreto Legislativo 1301, establece que podrá postular a ser colaborador eficaz quien se haya disociado de la actividad criminal y manifieste su voluntad de proporcionar la información eficaz.

En tal sentido, como criterio delimitador previo al inicio de la fase de corroboración, es necesario que la información proporcionada por el aspirante a colaborador eficaz tenga caracteres de verosimilitud y coherencia que permita justificar el inicio de la fase de corroboración, por lo que, en este escenario no se pediría que la información sea suficiente en grado de verdad necesario para sostener un acuerdo de colaboración, sino solo en grado indiciario. En ese sentido, la doctrina española en referencia a la declaración del coimputado, ha señalado que la corroboración solo tendría sentido en cuanto la información sea por lo menos creíble o tenga caracteres de verosimilitud (Lozano,2013) (Miranda, 2012). 


\section{Sub fase de diligencias de corroboración o verificación}

\section{a. Precisión del objeto}

En este aspecto, conviene precisar que las diligencias de corroboración realizadas por la Policía Nacional de ser el caso, bajo la dirección del Ministerio Público, se rigen bajo las formalidades del CPP de $2004 \mathrm{y}$, por lo tanto, es necesario que cuenten con un objeto determinado.

Si nos remitimos al artículo 11 del Reglamento del Decreto Legislativo 1301, se ha previsto que el inicio del proceso de colaboración eficaz, se realiza mediante una disposición debidamente motivada que deberá contener entre algunos elementos, tres que consideramos importantes: 1. Si el aporte ofrecido podría ser eficaz; 2 . Si la información puede ser corroborada y 3 . Si permitirá alcanzar alguno de las finalidades del artículo 475 del CPP de 2004. Dicho esto, el objeto de las diligencias de corroboración comprenderá la obtención de todos aquellos datos o elementos corroborativos que permitan acreditar si la información proporcionada cumple estos tres elementos, las cuales partirán siempre desde la premisa de que la información aportada por el aspirante a colaborador no es fiable.

Para ello, como recomendación demos recurrir a la experiencia italiana que cita Sferlazza (2006), que al respecto ha señalado que:

\footnotetext{
El Ministerio Público tiene que recoger la indicación de todos los episodios sobre los que el colaborador es capaz de referir: tendrá que hacerlo de manera obviamente sintética y dando autonomía a cada hecho, permitiendo la gradual difusión de partes específicas de la misma acta, que deberán ser alegadas a la entrega relativa los crímenes específicos para demostrar que el colaborador no ha realizado declaraciones tardías. Según la jurisprudencia, los 180 días dentro de los que el colaborador tiene que proveer todas las noticias de que está en posesión, parten del momento de la formación del acta explicativa. (p. 144).
}

En tal sentido, siguiendo la experiencia italiana, el éxito de la fase de corroboración dependerá de la precisión de la naturaleza de los hechos a corroborar y cuáles serían las diligencias más idóneas para determinar la verosimilitud de estos hechos.

\section{b. Sobre la inexistencia de contradicción en las diligencias de corroboración o verificación}

Tal y como lo hemos expuesto anteriormente, la doctrina española crítica la fiabilidad probatoria de la información obtenida a partir de la declaración del colaborador, debido a la no participación del delatado en cuanto a la posibilidad de que su defensa pueda interrogar al aspirante a colaborador eficaz. Es decir, no se exige la vigencia del principio de contradicción, pero, aun así, la información que se aporte y obtenga en dicho proceso pueden ser utilizados en los procesos penales conexos.

Desde nuestra perspectiva, el objeto del proceso especial de colaboración eficaz no es la confesión y ni siquiera la condena o el beneficio otorgado al colaborador, sino que, es la información que pueda obtenerse del acuerdo negociado. En ese sentido, la Corte Suprema ha establecido que:

la colaboración eficaz es un proceso especial
autónomo, no contradictorio, basado en el
basado en el principio del consenso entre las
partes y la justicia penal negociada, que tiene
por finalidad perseguir y/o controlar eficazmente
la criminalidad. En otras palabras, el proceso
por colaboración eficaz es un mecanismo por
el cual el colaborador brinda información útil y
relevante que contribuye a descubrir la estructura
organizacional, la forma de actuar, sus planes y las
personas que la integran, neutralizando con estos
datos la actividad delictiva de la organización
criminal, posibilitando la entrega de los bienes
o instrumento utilizables en la comisión de
delitos o ubicar los activos maculados. (Corte
Suprema de Justicia, Casación $N^{\circ}$ 852-2016-
Puno, fundamento 8).

Aun cuando coincidamos con la doctrina que ha tratado el tema al afirmar que el proceso de colaboración eficaz no podría ser considerado un proceso, por la carencia precisamente de los elementos inherentes que la doctrina ha desarrollado como: pretensión, contradicción $\mathrm{y}$ no jurisdiccionalidad (Asencio, 2018); $\mathrm{y}$, en consecuencia, más cercano a un procedimiento o especialidad procedimental en todo caso. Nuestra posición es que, finalmente, debe garantizarse que la información proporcionada que es el objeto del proceso penal pueda ser lo más fiable posible mediante la fase de corroboración correspondiente.

En consecuencia, la falta de no contradicción por parte del delatado en el procedimiento de 
corroboración en la colaboración eficaz

Two reflections for the dogmatic construction of the corroboration

phase in effective collaboration

colaboración eficaz, se encuentra justificado en la medida de que la obtención de la información que ha superado los filtros de la fase de corroboración solo tendría calidad de elemento de convicción o medio de prueba, cuya fiabilidad y grado de probabilidad pueden ser sometida a contradictorio en el proceso penal conexo por parte de las partes procesales, que incluye al delatado. En ese escenario se puede debatir otras cuestiones como el mantenimiento de alguna medida de protección que se le haya impuesto al colaborador como la reserva de identidad e inclusive la necesidad de interrogarlo.

Por tanto, dada la finalidad de este procedimiento o proceso especial - como se le denomina al CPP de 2004 -, la participación del delatado en la fase de corroboración, mediante la posibilidad de interrogar al aspirante a colaborador eficaz, podría generar riesgos de intimidación o inclusive atentar contra la integridad del aspirante a colaborador, por lo que, resulta coherente que sea en el proceso penal conexo donde se permita la contradicción al delatado.

\section{c. El plazo razonable de la fase de corroboración o verificación}

En la regulación de la colaboración eficaz en el CPP de 2004, no existe normativa expresa respecto a la duración del proceso especial de colaboración eficaz y mucho menos de la fase de corroboración. Si revisamos la exposición de motivos del Decreto Legislativo $\mathrm{N}^{\circ} 1301$, veremos que no existe referencia alguna a dos aspectos que consideramos centrales, el primero sobre el plazo del procedimiento y el segundo sobre la fase de corroboración. Por ello, necesariamente debemos recurrir a la experiencia comparada para encontrar motivos razonables y dar una propuesta plausible.

Desde el derecho comparado, vemos que en Italia se ha establecido como plazo legal máximo de 180 días para que el colaborador entregue y explique toda la información que maneja, que comenzará desde el inicio de colaboración y la cual constará en el acta explicativa (Sferlazza, 2006). Cabe señalar, que no se precisa que este plazo corresponda a la fase de corroboración de la información, pero por su modelo de regulación entendemos que comprende esa fase incluyendo la de negociación; asimismo, este plazo se ha considerado como un requisito necesario y la sanción de su incumplimiento ha sido su inutilización.

Por otro lado, en Brasil, de manera similar se ha establecido que el ofrecimiento de denuncia o el proceso penal relativo al colaborador podrá ser suspendido por el plazo de 6 meses, los cuales, pueden ser prorrogables hasta que sean cumplidas todas las medidas de colaboración, lo que suspende el plazo de prescripción de la acción penal (Lei 12850, artículo 4 inciso 3). Es decir, que como máximo se ha establecido el plazo de 1 año que debe durar todo el procedimiento de colaboración, desde que se inicia la fase de negociación hasta la homologación del acuerdo por parte del juez.

En ese sentido, consideramos que nuestra normativa afronta un grave problema relativo a la carencia de una disposición específica respecto al plazo general del procedimiento de colaboración eficaz y, a la vez, de las sub fases que no han sido delimitadas; quizás esta falta de regulación, ha motivado interpretaciones que propugnen una utilización más célere de la información aportada por el colaborador eficaz, llevando inclusive a utilizarla sin que haya sido completamente corroborada ni sometida al control judicial.

En este contexto, el Ministerio Público ha emitido una instrucción general de cómo afrontar esta problemática $\mathrm{y}$, de manera general ha señalado:

7.3.1.- El fiscal debe velar que el proceso de colaboración eficaz se realice en un plazo razonable. Para tal efecto:

a) El Fiscal procurará que la información proporcionada por el colaborador sea realizada de manera inmediata, oportuna y continua.

b) La corroboración debe darse de manera inmediata a la información proporcionada por el colaborador.

c) Luego de la corroboración, se debe establecer un cronograma que permita conocer a los participantes la duración máxima de la etapa de negociación. El mismo que puede ser programado conforme a la naturaleza del proceso.

7.3.2.- Se pueden firmar convenios preparatorios que establezcan cronogramas de las acciones a realizar a fin de presentar el acuerdo en breve plazo. (Ministerio Público, Instrucción General $\mathrm{N}^{\circ}$ 1-2017-MP-FN, punto 7.3.) 
Conforme a esta instructiva cuyo aporte, ciertamente, se ha emitido con la mejor de las intenciones, consideramos brindar unas pautas adicionales respecto al tema en específico de la corroboración que podrían servir de apoyo interpretativo, puesto que es un aspecto muy importante que inclusive puede condicionar:

- El proceso de colaboración eficaz como hemos señalado antes, se rige bajo las reglas generales del proceso penal común en lo que le sea aplicable.

- En tal sentido, en los casos de gran complejidad como lo son los de crimen organizado, consideramos que las diligencias de corroboración no deben durar más allá de los 8 meses, a partir de que se conozca la información proporcionada por el aspirante a colaborador, en atención a que las diligencias pueden revestir de dificultades para su acreditación.

- No obstante, se puede ampliar el plazo en caso de que se necesite la actuación de una diligencia indispensable de corroboración. En todo caso, dicha ampliación debe ser razonable en atención a la eficacia y motivado mediante una disposición fiscal.

Para finalizar esta segunda reflexión, queremos precisar que esta elaboración de elementos esenciales para la fase de corroboración o verificación serviría de base, para que el Fiscal pueda analizar la información aportada por el colaborador eficaz junto a la información que la verifica o corrobora aplicando un razonamiento corroborativo necesario para reducir los peligros ya advertidos, sobre los cuales no existe ningún control y que han sido motivo de crítica en el apartado correspondiente.

Así pues, la construcción de un razonamiento corroborativo constituye una tarea pendiente que podría ayudar a reducir la desconfianza sobre la información que aporta el aspirante a colaborador eficaz, con la finalidad de que solo aquella información que supere estos filtros pueda ser utilizada para sustentar medidas cautelares personales o reales, medidas limitativas de derechos o una sentencia condenatoria. Asimismo, es recomendable que dicho razonamiento tenga que ser controlado judicialmente, por lo que, la motivación de este razonamiento bien puede ser una exigencia compatible y aceptable para tal caso.

\section{CONCLUSIONES}

- El modelo de colaboración eficaz como proceso especial asumido por el CPP de 2004, dispone de una fase de corroboración de la información que aporta el aspirante a colaborador eficaz, la misma que no ha merecido atención ni de la dogmática procesal penal, ni de la jurisprudencia nacional.

- La amplia discrecionalidad del Fiscal para determinar el estándar de corroboración de la información aportada por el aspirante a colaborador eficaz, posibilita la existencia de riesgos como la presencia de sesgos de confirmación en la corroboración de la información, así como la posibilidad de que el aspirante a colaborador pueda aportar información falsa o que se realicen diligencias de corroboración ilícitas.

- El análisis de la fase de corroboración o verificación en la colaboración eficaz, debe partir desde una perspectiva epistemológica destacando la importancia de esta fase para reducir los riesgos y la desconfianza que desde el inicio se tiene sobre la declaración de un aspirante a colaborador eficaz.

- El respeto a la voluntariedad y la defensa penal efectiva del aspirante a colaborador eficaz desde las reuniones informales y la evaluación de su idoneidad para brindar la información, constituyen las condiciones mínimas requeridas para que se inicie la fase de corroboración o verificación de la información aportada.

- La precisión del objeto de las diligencias de corroboración, destacando la idoneidad de las mismas para encontrar elementos de corroboración que verifiquen o no la información aportada, así como, la determinación de un plazo razonable para dichas diligencias que incluyen las reuniones de negociación, son elementos esenciales que deben desarrollarse dogmáticamente a fin de cumplir con la finalidad de la colaboración eficaz: conseguir información eficaz, útil y oportuna para el desbaratamiento de las organizaciones criminales. 


\section{REFERENCIAS BIBLIOGRÁFICAS}

Asencio, J. M. (2018). El procedimiento por colaboración eficaz. La ilícita e inconstitucional incorporación de sus actuaciones al proceso penal. En Asencio, J.M. y Castillo, J.L. (Eds.), Colaboración eficaz (pp. 10 - 82), Lima, Perú: Editorial Ideas.

Binder, A. (1997) Política criminal, derecho penal y sociedad democrática. En: El mismo. Política criminal. De la formulación a la praxis. Buenos Aires, Argentina: Editorial AdHoc.

Castillo, J. (2017). La colaboración eficaz y su empleo en la prisión provisional. En: José María Asencio Mellado y José Luis Castillo Alva (Directores). Colaboración eficaz, prisión preventiva y prueba. Lima, Perú: Ideas Solución Editorial.

Devis Echandía, H. (2002). Teoría general de la prueba judicial. Tomo II. 5ta. Edición. Bogotá, Colombia: Editorial Temis S.A.

De La Jara, E. (2016). La colaboración eficaz contra el crimen organizado, entre lo permitido y prohibido por el Derecho (Tesis de maestría). Pontificia Universidad Católica del Perú, Lima, Perú. En página web: http://tesis.pucp.edu.pe/ repositorio/handle/20.500.12404/8372.

Ferrajoli, L. (1995). Derecho y razón. Teoría del garantismo penal. (Traducción de Perfecto Andrés Ibañez y otros). Madrid, España: Editorial Trotta.

Garapon, A. y Papadopoulos, L. (2008). Juzgar en Estados Unidos y en Francia. (Traducción de Viviana Díaz Perilla), $1^{\circ}$ edición en español. Bogotá, Colombia: Legis Editores S.A.

Gascón, M. (2004). Los hechos en el Derecho. Bases argumentales de la prueba. $2^{\circ}$ edición. Madrid, España: Marcial Pons.

Gómez, M. (2004). Criminalidad organizada y medios extraordinarios de investigación. Madrid, España: Editorial Colex.

González, J. (2007). El renacimiento del pensamiento totalitario en el seno del estado de Derecho: la doctrina del derecho penal del enemigo. Revista Penal, 19, pp. 52-69.
Kahneman, D. (2017). Pensar rápido, pensar despacio. Ciudad de México, México: De Bolsillo.

Langbein, J. (2001). Tortura y plea bargaining (traducción de María Lousteau y Alberto Bovino). En: Julio Maier y Alberto Bovino (Comps.). El procedimiento abreviado. Buenos Aires, Argentina: Editores Del Puerto.

Laudan, L. (2013). Verdad, error y proceso penal. Un ensayo sobre epistemología jurídica. (Traducción de Carmen Vásquez y Edgar Aguilar). Madrid, España: Editorial Marcial Pons.

Lozano, M. (2013). La declaración de los coimputados. Navarra, España: Editorial Arazandi.

Lupo, S. (2016). Historia de la mafia. Desde sus orígenes hasta nuestros días. (Traducción Stela Mastrangelo). Ciudad de México, México: Fondo de Cultura Económica.

Miranda, M. (2012). Prólogo. En: Alonso Peña-Cabrera Freyre. Los procesos penales especiales y el derecho penal frente al terrorismo (pp. 9 - 11). Lima, Perú: Editorial Idemsa.

Muñoz, J. (2008). De las prohibiciones probatorias al Derecho procesal penal del enemigo. Buenos Aires, Argentina: Editorial Hammurabi.

Muñoz, A. (2011). La influencia de los sesgos cognitivos en las decisiones jurisdiccionales: el factor humano. Una aproximación. Indret: Revista para el análisis del Derecho. 2(1). Recuperado de: http://www.indret.com/ pdf/820_es.pdf.

Nieva, J. (2012). Fundamentos de Derecho procesal penal. Buenos Aires, Argentina: Editorial BdeF.

Andrés, P. (2009). Prueba y convicción judicial en el proceso penal. Buenos Aires, Argentina: Editorial Hammurabi (2010) La valoración de la prueba. Madrid, España: Marcial Pons.

Ore, A. (2016). Derecho procesal penal peruano. Tomo III. Lima, Perú: Editorial Gaceta Jurídica. 
Ortiz, J (2018). Los delatores en el proceso penal. Recompensas, anonimato, protección $y$ otras medidas para incentivar una "colaboración eficaz" con la Justicia. Madrid, España: Wolters Kluber España S.A.

Páez, A. (2019). Los sesgos cognitivos y la legitimidad racional de las decisiones judiciales. Recuperado de: https://philpapers. org/archive/PEZLSC.pdf.Consultado el 15 de abril de 2020.

Peña, R. (1997). Procesos penales especiales. Nuevas tendencias en el proceso penal peruano. Lima, Perú: Editorial San Marcos.

Portilla, G (2004). Fundamentos teóricos del derecho penal y procesal-penal del enemigo. Jueces para la democracia, 49, pp. 43-50.

Ragués, R. (2006). ¿Héroes o traidores? $\mathrm{La}$ protección de los informantes internos (whistleblowers) como estrategia políticocriminal. Indret 364 (3), pp. 1-19.

Real Academia Española. Diccionario de la lengua española. $23^{\circ}$ edición. Recuperado de: https://dle.rae.es/corroborar.

Riquert, M. (2011). La delación premiada en el Derecho penal. El arrepentido "una técnica especial de investigación” en expansión. Buenos Aires, Argentina: Editorial Hammurabi.

Rodríguez, N. (1997). La justicia penal negociada. Experiencias de Derecho comparado. Salamanca, España: Ediciones Universidad de Salamanca.

Rojas, F. (2012). Alcances y cuestiones generales del procedimiento especial de colaboración eficaz en el nuevo código procesal penal. Revista Derecho \& Sociedad. 39 (1), pp. 52-60. Recuperado de: http://revistas.pucp. edu.pe/index.php/derechoysociedad/article/ view/13059/13671.

San Martín, C. (2015). Derecho procesal penal. Lecciones. Lima, Perú: INPECCP.

Sferlazza, O. (2006). Proceso acusatorio oral $y$ delincuencia organizada. Ciudad de México, México: Editorial Fontamara.

\section{LEGISLACIÓN Y NORMAS ADMINISTRATIVAS PERUANAS}

Gobierno del Perú. Congreso de la República (20 de diciembre de 2000). Ley $N^{\circ} 27378$. Ley que establece beneficios por colaboración eficaz en el ámbito de la criminalidad organizada. Recuperado de: https://www.oas. org/juridico/spanish/per_res31.pdf.

Gobierno del Perú. Ministerio de Justicia. Decreto Supremo $N^{\circ}$ 015-93-JUS, Aprueba el Reglamento de la Ley del Arrepentimiento sobre Delito de Terrorismo. Recuperado de: http://www2.congreso.gob.pe/sicr/cendocbib/ con4uibd.nsf/3E9D3734B44BAC5005257BF 8008014F9/\$FILE/4.pdf.

Gobierno del Perú. Consejo de Ministerios (12 de mayo de 1992). Decreto Ley $\mathrm{N}^{\circ} 25499$, Establecen los términos dentro de los cuales se concederán los beneficios de reducción, exención, remisión o atenuación de la pena, a incursos en la comisión de delitos de terrorismo. Recuperado de: https://docs.peru. justia.com/federales/decretos-leyes/25499may-12-1992.pdf.

Gobierno del Perú. Consejo de Ministros (6 de abril de 1992). Decreto Ley $N^{\circ} 25418$ Ley de Bases del Gobierno de Emergencia $y$ Reconstrucción Nacional. Recuperado de: https://docs.peru.justia.com/federales/ decretos-leyes/25418-apr-6-1992.pdf.

\section{TRATADOS INTERNACIONALES}

Organización de las Naciones Unidas (2004). Convención Interamericana contra la Corrupción (B-58), suscrito el 29 de marzo de 1996, articulo 6. Recuperado de: http://www. oas.org/es/sla/ddi/tratados_multilaterales_ interamericanos_B-58_contra_Corrupcion. asp. Consultado el 8 de abril de 2020 .

Organización de las Naciones Unidas (2004). Convención de las Naciones Unidas contra la Delincuencia Organizada Transnacional y sus dos protocolos adicionales. Recuperado de: https://www.unodc.org/documents/treaties/ UNTOC/Publications/TOC\%20Convention/ TOCebook-s.pdf. Consultado el 25 de abril de 2020. 
Two reflections for the dogmatic construction of the corroboration

phase in effective collaboration

\section{LEGISLACIÓN INTERNACIONAL}

\section{ARGENTINA}

Senado y Cámara de Diputados de la Nación Argentina (2016). Ley 27304, modifica el Código Penal Argentino. Recuperado de: http://servicios.infoleg.gob.ar/infolegInternet/ anexos/265000269999/267115/norma.htm.

\section{BRASIL}

Cámara Dos Deputados (2 de agosto de 2013). Artículo 3 [Capítulo II]. Lei de Combate ao Crime Organizado [Lei 12.850 de 2013]. Recuperado de: https://www2. camara.leg.br/legin/fed/lei/2013/lei-12850-2agosto-20137767 14-norma-pl.html.

\section{COLOMBIA}

Congreso de Colombia (2019). Ley 906, por el cual se expide el Código de Procedimiento Penal Colombiano (Corregida de conformidad con el Decreto 2770 de 2004). Recuperado de: http://www.defensoria.gov.co/public/ Normograma\%202013_html/Normas/ Ley_906_2004.pdf.

\section{JURISPRUDENCIA NACIONAL}

Corte Suprema de Justicia, Casación N ${ }^{\circ} 852$ 2016-Puno. 